\title{
Effects of drinkometer current and of foot shock on psychogenic polydipsia'
}

EVALYN F. SEGAL, University of Illinois at Chicago Circle, Chicago, Ill. 60680, and DAVID L. ODEN, University of Pennsylvania, Philadelphia, Pa. 19104

The development of schedule-induced polydipsia in rats run on a free dry-food schedule was not affected by whether or not the drinkometer was operating. Other rats showed an increase in polydipsia when given occasional mild foot shocks, suggesting that polydipsia is enhanced by a nonspecific emotion-arousing procedure.

\section{EXPERIMENT 1}

A common method of recording drinking is by means of a drinkometer which passes a minute current through the animal every time it contacts the drinking tube. This raises the question of whether the current stimulation reinforces schedule-induced polydipsia. Falk (1964) said that it did not, but he did not supply data. We supplement Falk's comment with data from four rats.

Method

Four adult, male, albino rats, maintained at $80 \%$ of ad lib weight by food deprivation, were run for 13 days in sessions in which 100 Noyes $45-\mathrm{mg}$ rat chow pellets were delivered, one every $60 \mathrm{sec}$. A water bottle was always available. A Grason-Stadler drinkometer was attached to the water bottle and to the grid floor of the experimental chamber. When operating, it passed a minute current through the rat every time it contacted the drinking tube. During the first 11 sessions, the drinkometer was not on and so no current flowed through the rat when it drank. During the last two sessions, the drinkome ter was on.

Water consumption was read directly from the calibrated scale on the water bottle at the end of each session. Results

Figure 1 shows each rat's water consumption during daily experimental sessions. Consumption rose gradually and monotonically in all except Rat E-O from a low of about 1 to $25 \mathrm{cc}$ in the first session to a maximum of about 60 to $75 \mathrm{cc}$ in later sessions. Turning on the drinkometer during the last two sessions produced variable, and apparently nonsignificant effects.
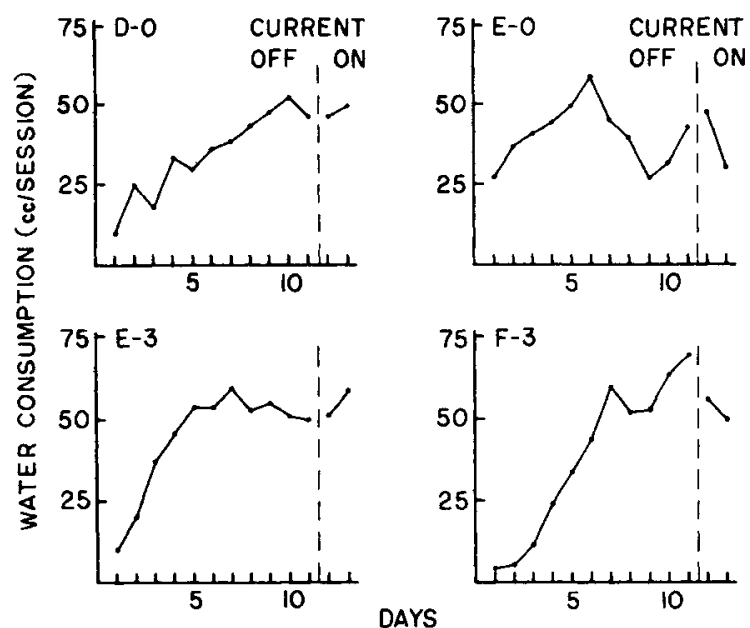

Fig. 1. Total daily water consumption in $c c$, without and with the operation of the drinkometer.
These data confirm Falk's (1964) comment that the drinkometer current does not influence schedule-induced polydipsia. Certainly the development of polydipsia does not depend on the drinkometer. Levels of polydipsia attained in the first 11 days of this experiment were comparable to those attained in earlier experiments where the drinkometer operated continuously from the beginning (e.g., Segal, Oden, \& Deadwyler, 1965a).

\section{EXPERIMENT 2}

We earlier suggested that one of the determinants of psychogenic polydipsia might be "an emotional state produced by having to wait for very small food portions to be doled out at long intervals" (Segal, Oden, \& Deadwyler, 1965b). The present experiment addresses this issue indirectly, by asking whether emotional arousal by another aversive event, electric foot shock, will interact additively with the hypothetical state aroused by the free-food schedule.

Method

Three adult, male, albino rats, maintained at $80 \%$ of ad lib weight by food deprivation, were made polydipsic by being given 25 Noyes $45-\mathrm{mg}$ rat chow pellets daily, at a spacing of 90 sec, in an experimental chamber that included a (nonoperative) bar, a water bottle, a grid floor through which shocks could be delivered, and a door which gave access to a running wheel. The rats were run for 29 days with free access to the running wheel, and no shock. Then the door to the wheel was shut, barring access to the wheel, and the present experiment began. Six baseline days were run, and then Shock Series 1 began. During the next seven sessions, two brief shocks of mild intensity, spaced $2 \mathrm{sec}$ apart, followed $60 \mathrm{sec}$ after the delivery of each food pellet. Fourteen baseline days followed, succeeded by Shock Series 2 , in which two brief shocks of slightly higher intensity followed $60 \mathrm{sec}$ after the delivery of the 5 th, $10 \mathrm{th}, 15 \mathrm{th}$, and 20 th pellets in each of 13 successive daily sessions. Following 24 more baseline sessions, Shock Series 3 began. In the first 10 sessions of the series (3A), two brief shocks of the same intensity as in Series 2 followed $5 \mathrm{sec}$ after the delivery of the 6th, 12th, 18th, and 24 th pellets. In the last nine sessions (3B), two brief shocks of the same intensity followed $45 \mathrm{sec}$ after the delivery of the 5 th, 10 th, 15 th, and 20 th pellets.

Water licks were recorded with a Grason-Stadler drinkometer attached as in Experiment 1. The drinkometer circuit opened during the delivery of foot shocks.

Results

Figure 2 shows each rat's total daily water licks during sessions. Circled points represent shock sessions. The experiment began after the rats had already had 29 days' exposure to the free-food schedule, and the data shown for the first six baseline sessions are comparable to the asymptotic level of polydipsia attained by about the 14 th of the previous 29 days. (That is, permitting or barring access to the running wheel had no obvious effect on polydipsia.) Rat NC's maximum number of licks in any of the previous 29 days was about 2000; Rat BE's, about 3500, Rat BK's, about 3000.

The effect of Shock Series 1 was to raise NC's licking rapidly to a high on the last session of about 6000 licks; BE's licking fell and then rose to a high of about 3800 ; BK's rose to about 4000 . During the baseline sessions following Shock Series 1 , no rat returned more than briefly to its original baseline. In fact, NC's and BE's licking rose even higher than in the preceding shock sessions. Shock Series 2 began, therefore, with a new, elevated baseline. During Series 2, NC's licking did 
reaching a plateau at the $58 \%$ correct response level around the 110th trial. Performance during the last 40 trials was significantly better than the first 40 trials $(t=2.69$, df $=7$, $\mathrm{p}<.05)$. The extinction function slopes sharply down to below chance level by the end of the first block of extinction trials. These results differ considerably from the usual rat discrimination learning curve in the lack of evidence of any negative acceleration.

Substantial individual differences in speed of learning as well as behavior was observed. Half of the Ss were quite tame by the end of the experiment. The other half still showed signs of fear when handled by the $E$. Two Ss reached the level of $75 \%$ correct responses around the 80 th trial, and two at about the 100th trial. The remaining Ss continued operating at chance level.

The results of the preliminary black-white discrimination situation was different from the study by Spigel \& Ellis (1965) who reported that frogs (Rana pipiens) preferred the black arm to either grey or white. It is clearly difficult to make meaningful comparison across species, as is shown by the difference in behaviors of even such closely related species as valliceps and woodhousii. The absence of even minimal data on most animals makes any serious comparative work sketchy at best.

\section{REFERENCES}

BROWER, L. P., \& BROWER, J. V. Z. Investigations into mimicry, Natural History, 1962, 71, 8-19.

SPIGEL, I. M., \& ELLIS, K. R. Brightness perference in the frog. Perceptual \& Motor Skills, 1965, 21, 367-370.

WILLIAMS, J. T., JR. A test for dominance of cues during maze learning by toads. Psychonomic Science, 1967, 9, 259-260.

$$
\text { NOTE }
$$

1. This experiment was supported by NSF Grant GY-4370 to the junior author. The authors express appreciation for the many helpful suggestions from William F. Pyburn, Professor of Biology, University of Texas at Arlington.

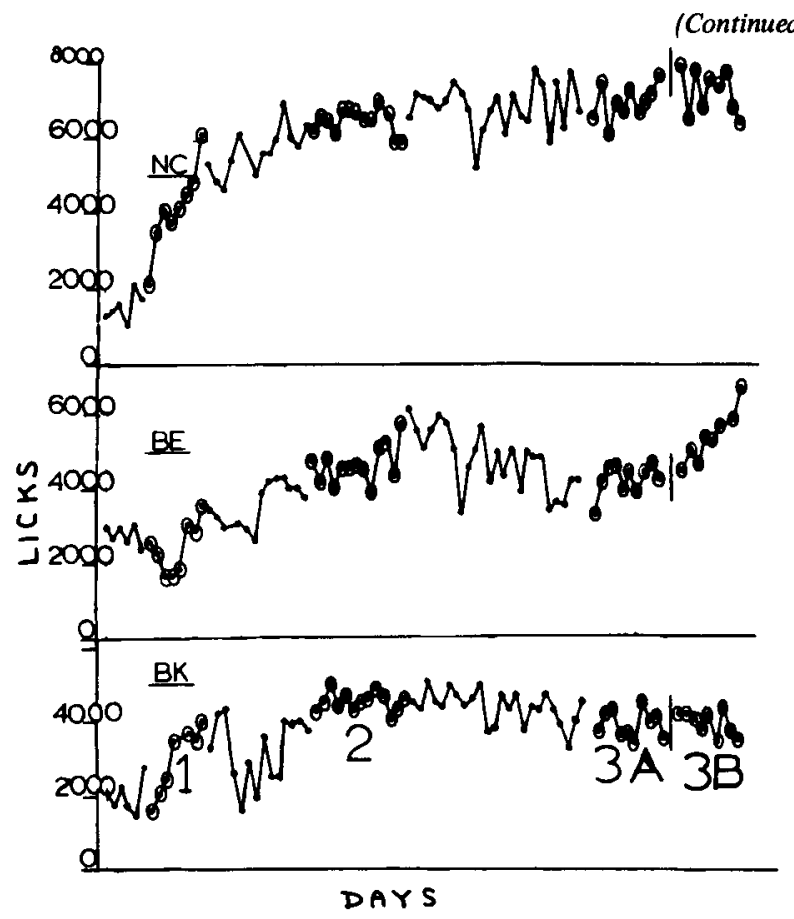

Fig. 2. Total daily water licks by each rat, without and with foot shock.

not increase above the the maximum of its new baseline, BK's increased to about 5000 licks, and BE's increased substantially, from a maximum in the immediately preceding baseline sessions of about 4200 licks to a new maximum of about 5800 . The baseline sessions that followed Series 2 showed still further elevations over previous baselines. Shock Series 3 had no significant effect in rats NC or BK, but elevated rat BE's licking still further, to a maximum on the last session of about 6300 licks. Although shock itself produced no marked effects in Rat NC in Series 2 and 3, there was a progressive rise in NC's drinking over the experiment, to a maximum close to 8000 licks in the last sessions.

The data suggest three conclusions. The first is that nonspecific emotional arousal by mild foot shock can enhance

\section{rom page 13)}

polydipsia. The second is that the enhancement remains or even increases after shock is discontinued. About $6000-8000$ licks probably represented an absolute maximum for this experiment. In the later sessions Rat NC was licking virtually all the time, except for very brief pauses to consume the pellets as they arrived. It could hardly have increased its licks further in the experimental time allotted, inasmuch as licking rate appears to be a constant in rats (Keehn \& Arnold, 1960; Schaeffer \& Premack, 1961). It may be that still further enhancement of polydipsia might have appeared, at least in Rat NC, had the experimental design permitted more time for licking.

The third conclusion is that at the mild shock intensities used, and even though shocks often arrived while the rats were actively drinking, the shocks had no effects on drinking that could clearly be described as punishing (unless the rise in drinking after shocks were discontinued be regarded as a delayed punishment effect-see Fig 11 in Azrin \& Holz, 1966, for a strikingly similar result in an experiment on punishment). Typically, when shocks came, the rats stopped drinking momentarily and then resumed. Having resumed, they continued drinking for longer periods than in the initial baseline sessions. This increase in duration of drinking persisted in subsequent baseline sessions, and accounts for the elevation in total licks per session.

\section{REFERENCES}

AZRIN, N. H., \& HOLZ, W. C. Punishment. In W. K. Honig (Ed.), Operant behavior: areas of research and application. New York: Appleton-Century-Crofts, 1966. Pp. 380-447.

FALK, J. L. Studies on schedule-induced polydipsia. In M. J. Wayner (Ed.), Thirst. New York: Pergamon Press, 1964. Pp. 95-116.

KEEHN, J. D., \& ARNOLD, E. M. M. Licking rates of albino rats. Science, $1960,132,739-741$.

SCHAEFFER, R. W., \& PREMACK, D. Licking rates in infant albino rats. Science, $1961,134,1980-1981$.

SEGAL, E. F., ODEN, D. L., \& DEADWYLER, S. A. Determinants of polydipsia: IV. Free-reinforcement schedules. Psychonomic Science, 1965a, 3, 11-12.

SEGAL, E. F., ODEN, D. L., \& DEADWYLER, S. A. Determinants of polydipsia: V. Effect of amphetamine and pentobarbital. Psychonomic Science, 1965b, 3, 33-34.

\section{NOTE}

1. These experiments were done at San Diego State College and supported by National Science Foundation Grants NSF GB 1605, NSF GB 5777, and NSF GB 7292. DLO ran the first experiment, and EFS ran the second with the assistance of David Brookshire and Michael Turner. 